\title{
Integrated digital prototyping in the fashion product development
}

\begin{abstract}
The research was set out to explore the effective integration of Digital Prototype in the product development process of the TCF industry, investigating the level of implementation of new digital technologies and especially 3D visualisation and virtualisation of a garment product comparing the enthusiasm, vision, scepticism, evangelism and restrained optimism between technology providers-vendors, entrepreneurs-independents, professional \& experienced users and academicsresearchers of clothing/fashion courses. A combination of primary and secondary sources was used. First hand interviews to investigate the level of technology implementation in the early adopters, the vision of the big corporations, entrepreneurs and professional users as well as the involvement of academics. Analysis of the collected primary and secondary data showed that on the one hand the traditional process of sample making has not changed but on the other hand fashion companies although using it, are facing many problems: time spent in developing and approving samples, lack of standardization of software solutions, and willingness to adopt new technology are some of them. It has been found that there has been a lack of research in the new dimensioned digital prototype of clothing at the product development level in a qualitative manner and from a perspective not so engineered-focused. Technology is revolutionary and overturning traditional processes. Therefore, the analysis of the effective integration of Digital Prototype in the product development process of the TCF industry is a key original factor of this paper.
\end{abstract}

Keywords: 3d virtual prototyping; product development; fashion and technology; integrated digital prototyping
Volume 3 Issue I - 2017

\author{
Evridiki Papahristou, Nikolas Bilalis \\ School of Production Engineering and Management, Technical \\ University of Crete, Greece
}
Correspondence: Evridiki Papahristou, Research Associate, School of Production Engineering and Management, Technical University of Crete, Kounoupidiana, Chania, Greece, Tel 306946332472, Email epapachristou@isc.tuc.gr

Received: April 01, 2017| Published: October 13, 2017

\section{Introduction}

Design, Development and Production have largely relied on the same, often manual, methods despite all the technological advances happening in the world outside of fashion and apparel. Ten years ago, academic research (by contrast to the existing 3D virtual software solutions) posited about clothing companies complaints' on the lack of effective garment-oriented CAD packages to design directly in 3D and provide the modellist with tools for shape modelling and cloth behaviour simulation. ${ }^{1}$ On the other hand, who studied the $3 \mathrm{D}$ garment design didn't focus on the ease value between the garment and the human body. ${ }^{2,3}$ Nowadays, with the growth of demand from better educated consumers, mass customization, e-commerce, advances in virtual reality applications, the virtual garment development is strongly desired in order to optimize apparel industry's design and development processes. According to Tao $\mathrm{X}^{4}$ from the down stream's point of view of the design process, 3D prototyping can greatly increase the potential of creation. However, the use of 3D prototyping solutions in the apparel industry is still lagging behind in comparison to other industries (such as, e.g. the automotive) although many vendor companies state that $3 \mathrm{D}$ prototyping once considered timeconsuming and cost prohibitive, today has the potential to develop innovative products with the optimal balance of style, quality and cost. ${ }^{5}$ The clothing industry once data-driven and silo-mentality oriented, is moving towards a model-driven approach with threedimensional offering the best representation of a product's identity.

This paper examines the effective integration of Digital Prototype in the Product development process. The authors investigated the level of the technology implementation in the early adopters, the vision of the big corporations, entrepreneurs and professional users for the global clothing and fashion industry as well as the challenges, opportunities and barriers that need to be overcome in order for digital prototype to accelerate business processes on an integrated basis. During the process of identifying everyone affected by a change initiative, the areas that will be impacted by the new involved technology implementation like 3D prototyping \& visualisation or PLM were grouped and according to their roles and relationships with the industry they have been divided in 4 groups:

a. Technology providers- vendors

b. Managers- executives- professional users

c. Entrepreneurs- independent user

d. Academics

\section{Approach to the problem (Methodology)}

This study has been motivated by two major factors. First, the predictions that the fashion and apparel industry is going to change in the next ten years as it have over the last 100 years. Technology is revolutionary and overturning traditional processes. In the product development process, new software tools are equipped with 3D visualisation capabilities, and promise an enabled more creative, innovation-based workflow. Digital prototype is at the core of this change due to being part of the speed-to market pressure in fashion companies. However, it has been shown that even if technology solutions like $3 \mathrm{D}$ and virtual prototype has been around for some time, and has been named disruptive, the industry has been slow on the uptake. Therefore, disruptive might not be the right word but lately embraced and much more embedded in the fashion industry. 
The second motivating factor for this study is that in general there has been a lack of research in the new dimensioned digital prototype of clothing at the product development level in a qualitative manner and from a perspective not so engineered-focused.

The next step was to form a semi-structured questionnaire with the topics of interest. The kind of questions asked followed nine types of qualitative interview questions: $^{6}$
i. Introducing questions
ii. Follow-up questions
iii. Probing questions
iv. Specifying questions
v. Direct questions
vi. Indirect questions
vii. Structuring questions
viii. Silence
ix. Interpreting questions

The research project gathered the opinions and experiences of experts with direct contact and use of the technology; the selection of the sample was purposive rather than random. 100 Experts from four different backgrounds of the fashion industry were selected to participate in this survey contacting personal interviews. As Figure 1 shows, 43 "relatively unstructured" personal interviews were carried out; some of them in typing due to lack of time on their behalf or the time difference between countries. 34 didn't respond at all, although they have been contacted with a coming-up e-mail twice. In the Figures 2-5 participants are categorized in some demographics; Gender, Age Group, Country of work and Occupation.

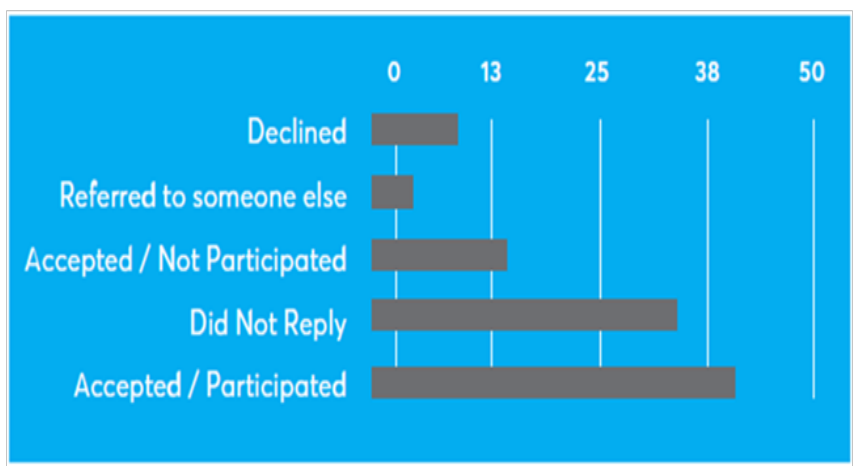

Figure I Interviews- Attribute Response.

The collection of primary data was not only relied on personal interviews but on surveys, notes, fieldwork and a combination of information types. The software NVivo was chosen as a state-of-theart analysis tool for qualitative and mixed methods research.

There are some points that need to be noted: The context of the questionnaire was changed in the process as interviews started to evolve. The interaction with the participants raised more and different issues than the ones that the survey initially started with. The openended, discursive nature of the interviews permitted an iterative process of refinement, whereby lines of thought identified by earlier interviewees were taken up and presented to later interviewees.
The way of interviewing had the following aesthetic:

i. The approach was structured to maximize the reliability and validity of measurement of key concepts

ii. The order of questions varied and even the wording. New questions were asked following up interviewees' replies

iii. It was conducted in a flexible way responding to the direction in which interviewees took the conversation

iv. In some cases, interviewees were interviewed more than once

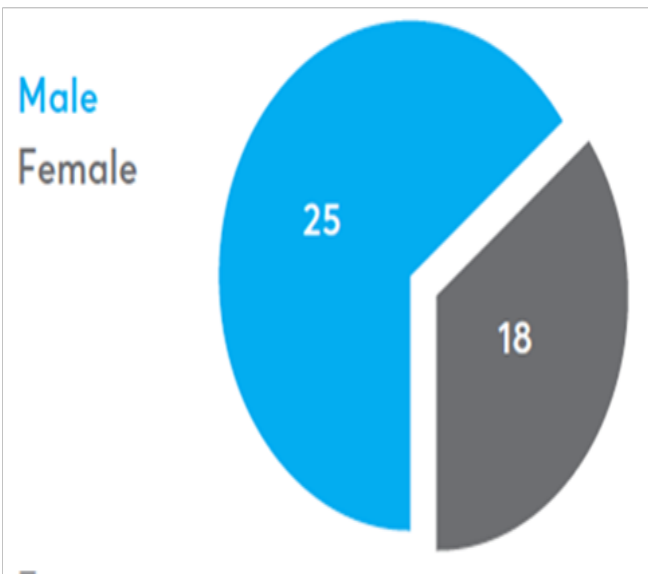

Figure 2 Interviews- Attribute Gender.

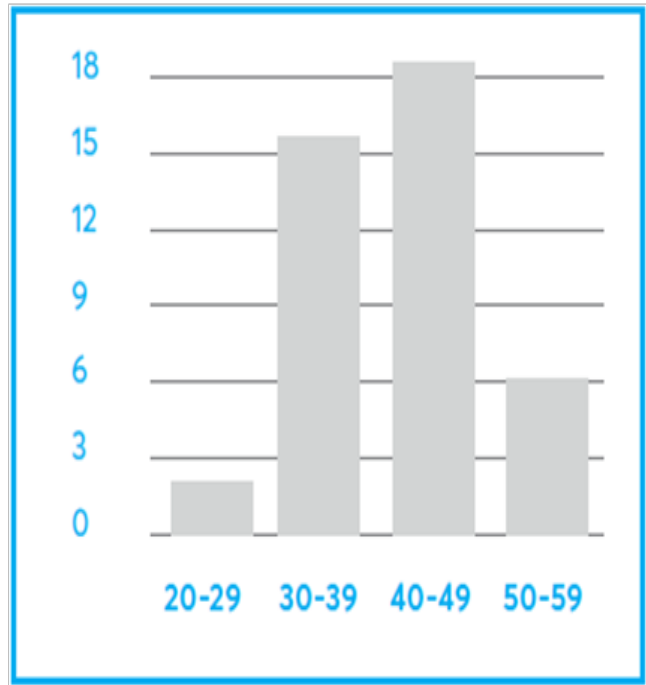

Figure 3 Interviews- Attribute Age Group.

\section{Traditional garment sample development process}

Most manufacturers begin the design phase in the traditional manner with stylists' creative ideas originating essentially from a 3D shape (a 3D conceptual idea in mind or a completed garment already existing) from which 2D information are extracted, such as 2D sketches, 2D patterns with corresponding fabric layers (3D-to$2 \mathrm{D}$ stage). Some designers still use pen and paper as design tools but the introduction of powerful and relatively inexpensive computers, systems, and graphics software such as Photoshop, Illustrator, and CorelDraw has encouraged the textile and clothing industry to use this versatile medium to help create and develop their designs 
(technical illustrations and visuals), presentations and clothing ranges, and manage their workflow. ${ }^{7}$ Other companies have integrated powerful CAD apparel and textile suites in all the areas of the product development process from textile and fashion design, pattern making, grading, garment production through to merchandising, and data management.

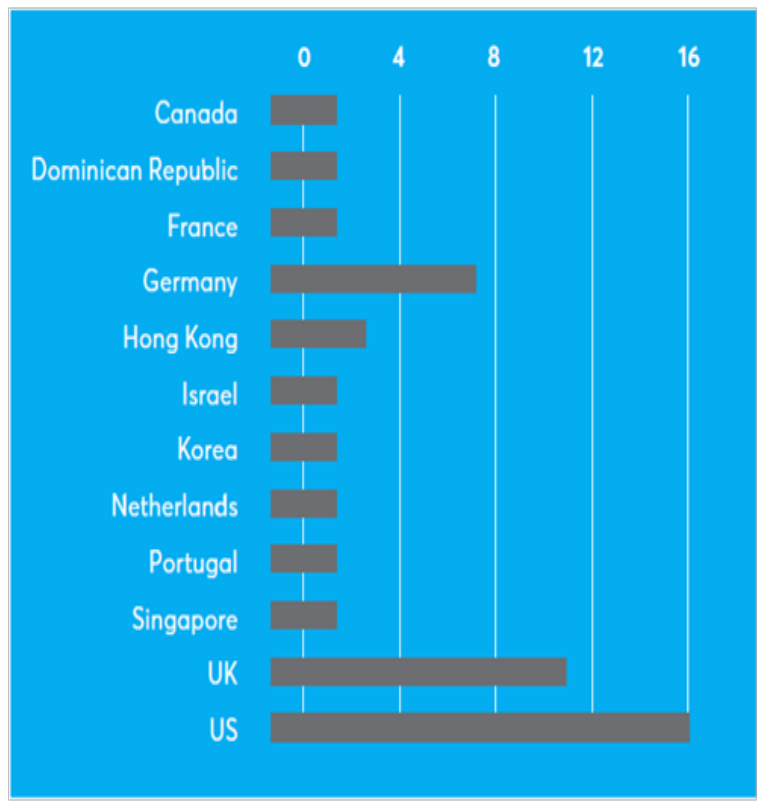

Figure 4 Interviews- Attribute Country of Work.

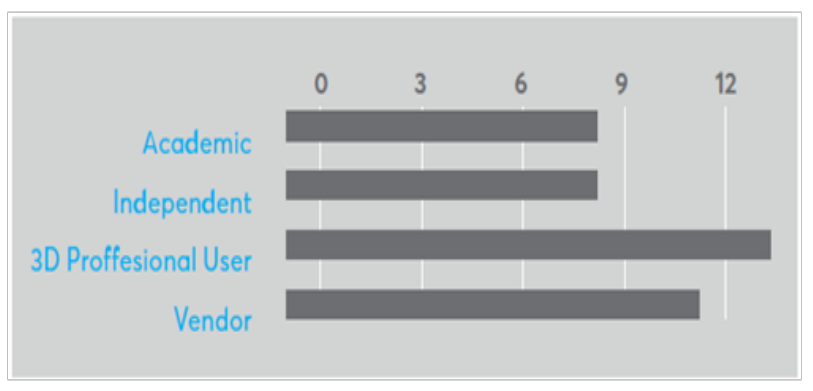

Figure 5 Interviews- Attribute Occupation.

The research proposes that the traditional process of sample making has not changed. On the other hand, Lectra states that now the traditional product development process no longer works. "Automating previously manual processes certainly has its advantages, but basic technology is just not enough to compete in today's market. Change and agility need to accompany new technology". ${ }^{8}$ Heikki Haldre, CoFounder of fits.me addresses that the traditional prototype process certainly works. It is just as expensive as it was before. It certainly works, companies certainly use it however the newer systems could provide additional benefits, like making it faster and making it cheaper. ${ }^{9}$

The problem though is that the old way of working is already set. Zara, one of the largest retailer, has already set a way of products to fit as fast as they have managed; new technology like 3D virtual prototyping or $3 \mathrm{D}$ visualisation was not available when that certain way was set. They have found how to create products without going into this technology. However, that doesn't mean that there aren't any benefits of it; with so many samples in the product development, the problem still exists, explains the CEO of a start-up company for an open source product development in Fashion industry. It is just whether companies are serious enough to look into it or whether they want to concentrate currently on the retail side since all of the sudden there is so much technology that has been made available; then gradually shift towards the other end. As most of the participants in the research pointed, the change is happening yes but it's happening slowly.

\section{Problems facing today}

As it has been several times noted, fashion is a very traditional industry-unlike other industries. But not all tradition needs preserving-especially not the currently chaotic manufacturing system which involves a lot of time, money, and guesswork.. According to Dhapodkar GS, ${ }^{10}$ the biggest problem in the garment industry today is (a) the time spent in developing and approving samples, ${ }^{11}$ agrees that approved samples are delayed due to (b) the lack of standardization of software solutions, and the detachment of the designer from production processes, along with the above poor specification, which lead to queries sent back through the chain to the designer with substantial waste generated through inadequate interpretations of the design. Three-dimensional (3D) technology-while well established in many other industrial sectors like aerospace, architecture and industrial design-is still relatively new to the fashion industry. 3D technology started to get in that market but needed technology advancements to get there. ${ }^{12}$ Developed a 3D sketch input method for the design of the garment pattern to fit the $3 \mathrm{D}$ human model but still, they were not effective in supporting design modifications. ${ }^{13}$ Updated algorithms $\mathrm{s}^{14}$ provided $3 \mathrm{D}$ garment fitting simulation the ability to react to the $2 \mathrm{D}$ pattern modification efficiently and speedily without the need to repeat the entire simulation for every modification. Others, ${ }^{15}$ used parametric curves to control the silhouette of garment's shape more easily. Lately ${ }^{16}$ tried to solve the problem to generate customized apparel products for individuals with variant body shapes with a flexible shape control technique ${ }^{17}$ recognizes that the apparel sector as a whole is lagging behind in its (c) willingness to adopt new technology to aid the product develop process, despite there being many innovative products on the market. It's time that fashion companies change their ways and follow vital digital transformations to embrace the tech revolution already happening in other industries. ${ }^{18}$ This is the only way that the industry will overcome the problem of (d) communication between factories which is often difficult, delayed, and problematic. The last but not least, major problem is (e) to achieve fit. ${ }^{10}$ Without fit garment has no commercial value. Once the style is received from the buyer, samples are sewn, shipped overseas, and a fit session is arranged with a live model that the manufacturer rarely sees. Inaccurate fit forms and lack of communication cause a lengthy approval process. Very rarely, the first sample is selected as the final sample.

Participants in the research discussed all the above mentioned problems. However, they have given another perspective. As to the problem of the immature software solutions (b), the Digital Creation Leader of a Leading Sportswear Company, comments that even if you have the software, it is not enough. You have to think what is your process, what are the requirements for manufacturers when they submit models, how to communicate (d). Big corporations who have started to work on finding digital standards very early on, have learnt they need to build a complete new process plus a complete language in their creation process- design, product management, development and manufacturers need to be in-forced as well. 
The founder and CEO of a start-up app who wants to standardise design communication between garment industry parties, singles out the major problem as the touch and feel part of the visualisation of the digital garment. Three-dimensional (3D) technology is well established in architecture and aerospace but "you don't need to touch the wing of the place or you don't need to touch the wall in order to visualise it". In apparel however, major complexities like the draping, the texture of the fabric, the softness, the harshness, each yarn which drapes differently on the body, haven't been able to be solved. He agrees that the new generation of software products that are coming out have looked it as a regard on how materials going to drape on the body. The advancements on it have not gone to the extend on making it easier for people to replace the older ways of looking at the samples or fitting the samples. "That hasn't been replaced completely or hasn't gone to that extend yet". ${ }^{19}$

Regarding the problem (c) willingness to adopt new technology, the Worldwide Marketing Manager of a software vendor company agrees that the fashion industry has not been so pro-active in changing the way it works. It's quite bizarre because it's an industry that is dealing with change but at the same time in its' process and in the way of work it is an industry reluctant to change. People are not very innovative in terms of way of working. This specific problem has been classified by the majority of the participants in the research as a challenge.

As for the problem of fit (e), we have gone one step ahead asking the participants why customers who have been convinced to buy clothing on-line, have been difficult to convince them to keep them. Studies say that 1 -in- 4 garments are returned and $50 \%$ of the returns are due to poor fit. The VP of a Body measurement system explains that the reasons can be several and "it does not fit" is sometimes an easy return excuse. On the retail side, customers are ordering two sizes and returning one- or there is no size that really fits the particular customer. It could also be that the customer just doesn't like the product and it is not a fit problem. An academic professor with a professional background research in sizing and fit of apparel and the use of three-dimensional body scanning in the apparel industry gives two reasons for the number of returns. It could be one or both of them; 1), customer cannot find an appropriate well fitted garment because the apparel industry doesn't provide it for their particular proportions and bodices or 2) the right garment exists but the communication size and fit is not sophisticated enough for them to be able to get that garment. There is the size and there is the communication of the size. Of course virtual fitting is a good way to approach the communication of the size.

It is concluded that the garment industry faces many problems. Fashion companies were working like they used to, 20 years ago. The market has changes. The consumer does not want the same things; he/ she wants to have new products all the time. The apparel collection may be smaller, but there are more of them. This means more size, colours, and variations to manage. If we multiply that by the many geographic versions where the company is present, the complexity increases further. Automating manual processes certainly confers an advantage, but to really compete today, basic technology is just not enough. Companies need to test new products before they start to incur real production costs. With all the digital technology and the e-commerce, shopping has become totally different. Change and agility are needed to accompany new technology in order to overcome the silo mentality that has reigned for so long in the fashion and apparel industry.

\section{Main differences between 2D and 3D processes}

In summary, a customer gives to the factory a tech pack with information for what the product is going to look like, what the measurements are supposed to be and the pattern maker /operator creates a 2D pattern to fit to your target customer, cuts it in fabric, sews it, tries it on, sends it back to the customer, makes corrections then return it, make other iterations and then again do the fitting on a real model until the final sample is approved. With this process the visualisation part of a finished garment, in the initial stages of the process, is missing and only great pattern makers can look at a $2 \mathrm{D}$ pattern and guess what it will do on the form. Usually, a physical sample is needed.

With the 3D process, the steps until the 2D pattern are the same. "The file with the $2 \mathrm{D}$ pattern is sent to the $3 \mathrm{D}$ operator, opened in the 3D software tool, select the fabric properties, place the pieces around the body, electronically stitch the pieces together, drape the garment, and add animation. After the fit is approved, the 3D operator is free to add different colours, graphics, trims, etc to render movies and image files" argues the CEO and Founder of a 3D vendor company. ${ }^{18}$ Table 1 , summarises the most commented differences:

Table I Differences between 2D \& 3D processes

Established thinking
Visualisation of finished product
Photorealistic images with specular
maps of texture
Stand-alone tool
Simultaneous changes from 2D->
3D and vice versa
Traditional skills
No need of proficiency in garment
making
It is a long process

\section{How the traditional method of garment prototype has} been altered with 3D virtual technology

The research proposes on the one hand that the traditional process of sample making has not changed but on the other hand fashion companies although using it, are facing many problems: time spent in developing and approving samples, lack of standardization of software solutions, willingness to adopt new technology and the poor fit of clothing products are some of them. New software tools are equipped with $3 \mathrm{D}$ visualisation capabilities, and promise an enabled more creative, innovation-based workflow. Digital prototype is at the core of this change due to being part of the speed-to market pressure in fashion companies. All of the participants believe in the potential of 3D technology in the clothing industry with some being more optimistic than others. Trying to answer the question "With 
the use of 3D virtual technology, how the traditional method has been altered?" the research has shown that there are many different perceptions on the way the $3 \mathrm{D}$ prototyping technologies have changed (and to what extend) the traditional development process. However, the most interesting issue that came out of the research is that the industry (apart from being very slow in changing traditional methods) and especially those companies who have embraced 3D virtual as part of their development cycle, is that they experimented first with this technology starting from the development of the final garment trying to reduce samples. In the process, they piloted in the early stage of the concepts' design and presentation in order to enhance the creation phase. It seems at first that there are many different perceptions on the way the $3 \mathrm{D}$ prototyping technologies have changed (and to what extend) the traditional development process. In the process, they piloted in the early stage of the concepts' design and presentation in order to enhance the creation phase. In the Figure 6 we present the two engagements of the $3 \mathrm{D}$ technology in the product development process.

It becomes apparent that 3D Visualization and 3D prototyping tool needs to be defined; therefore, Figure 6 presents the differences of the two applications of $3 \mathrm{D}$ virtual technology; as a $3 \mathrm{D}$ visualisation tool and as a 3D prototyping tool. This Figure 6 was drawn from the answers of the participants with the goal to explain the thin line that exists between the two areas of application of 3D virtual technology in the apparel product development. As the CEO of Optitex, puts it, "The creation of 3D and the use of 3D". ${ }^{20}$

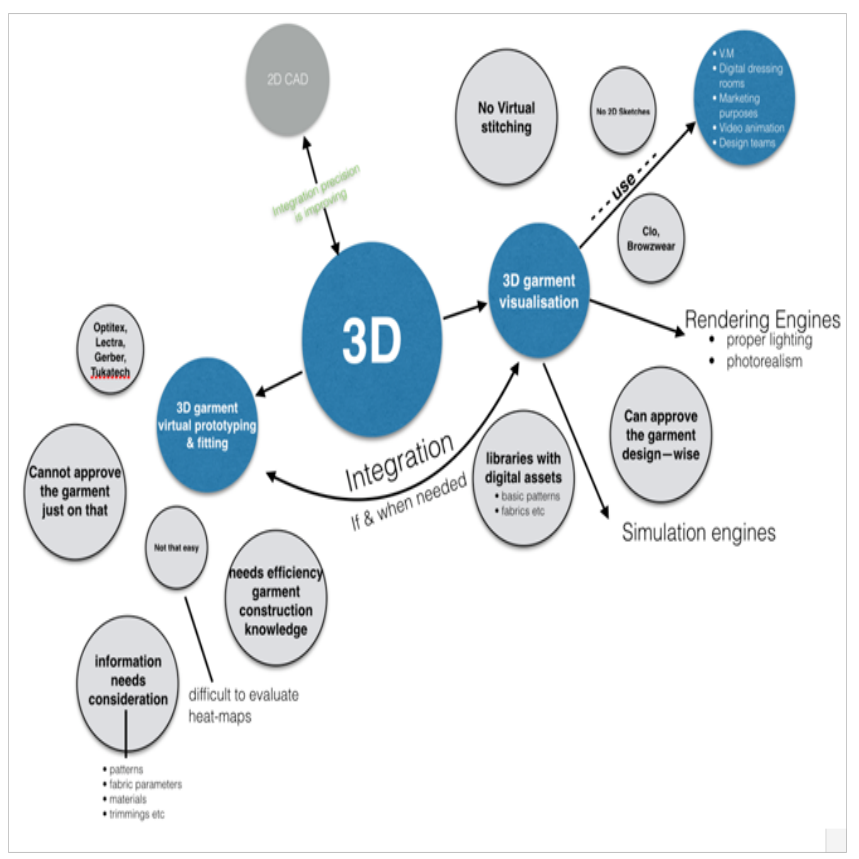

Figure $63 \mathrm{D}$ technology split in two- the creation and the use.

\section{Conclusion}

The most interesting issue that came out of the research is that the industry (apart from being very slow in changing traditional methods) and especially those companies who have embraced $3 \mathrm{D}$ virtual as part of their development cycle, is that they experimented first with this technology starting from the development of the final garment trying to reduce samples. In the process, they piloted in the early stage of the concepts' design and presentation in order to enhance the creation phase.
3D is certainly gathering real momentum and, according to many participants in the research, not before time. Early adopters of the technology like Adidas, Nike, UnderArmour, Target, Coach and many others who have already adopted 3D, have experimented for years with this new technology and are applying pressure on the vendors to produce solutions that work. One thing is certain: this technology is not the future; it's actually now. It is a promising technology that vows to shake the clothing industry, by making the line between "realities" and "virtual" fade even more. It continues to evolve at an increasing pace and as the research has shown; overcoming the problems and facing industry's challenges can only release its full potential to help transform the whole product development process of clothing products and even more.

\section{Acknowledgements}

This work has been carried out with the financial support of IKY (State Scholarships Foundation) Fellowship of Excellence for Postgraduate Studies in Greece-Siemens Programme (2012-2016).

\section{Conflict of interest}

Author declares there is no conflict of interest in publishing the article.

\section{References}

1. Fontana M, Rizzi C, Cugini U. 3D virtual apparel design for industrial applications. Computer-Aided Design. 2005;37(6):609-622.

2. Turquin E, Cani M, Hughes JF. Sketching garments for virtual characters. In Eurographics Workshop on Sketch-Based Interfaces and Modeling. 2004.

3. Zhong YQ. Fit and Tight-Fit Garment Design Based on Parameterized 3D Sketching. Spring Conference of the Fiber Society. 2009. p. $1320-1324$

4. Tao X, Bruniaux P. Toward advanced three-dimensional modeling of garment prototype from draping technique. International $J$ Clothing Science \& Technology. 2013;25(4):266-283.

5. Kvale S. InterViews: An introduction to Qualitative Research Interviewing. American J Evaluation. 1996;19(2):267-270.

6. Dassault Systemes. How IoT is Changing Human Interaction. 2015.

7. Burke S, Sinclair R. Computer-Aided Design (CAD) and Computer-Aided Manufacturing (CAM) of Apparel and other textile products. Textiles \& Fashion-Materials, Design and Technology. Woodhead Publishing; 2015. p. 671-703.

8. Lectra. A model for change-Part2: Transforming a Fashion business. 2014.

9. Haldre H. Personal Interview. 2015.

10. Dhapodkar GS, Gupta B. Education and Training of Skills of Pattern Making and Construction to Aspiring Candidates for apparel Industry. The 88th Textile Institute World Conference 2012, 15th-17th. Selangor, Malaysia; 2012.

11. McCann J. Translating the hybrid methodologies and practical outputs of smart textile-oriented research, in clothing for the growing ageing market, for the benefit of all stakeholders. The textile institute 88th world conference 2012: Conference proceedings. Textile Institute. 2012.

12. Elias J. Can this company get the retail fashion world online? 2014.

13. Wang CCL, Wang Y, Yuen MMF. Feature based 3D garment design through 2D sketches. Computer Aided Design. 2003;35(7):659-672. 
14. Luo Gang Ze, Yue MMF. Reactive 2D/3D garment pattern design modification. Computer Aided Design. 2005;37(7):623-630.

15. Wang J, Lu G, Li W, et al. Interactive 3D garment design with constrained contour curves and style curves. Computer-Aided Design. 2009;41(9):614-625.

16. Meng Y, Wang CLC, Jin X. Flexible shape control for automatic resizing of apparel products. Computer-Aided Design 2012;44(1):68-76.
17. Walter L, Kartsounis G, Carosio S. Transforming Clothing Production into a Demand-driven, Knowledge-based, High-tech Industry. London: Springer; 2009.

18. Court F. Embracing Digital Is a Matter of Survival, The Business of Fashion. 2015.

19. Kochar S. Personal Interview. 2016.

20. Landau A. Personal Interview. 2016. 